\title{
EL SER INDÍGENA-CAMPESINO DENTRO DEL CONTEXTO HISTÓRICO DE MÉXICO: UN ACERCAMIENTO A LAS PERSPECTIVAS INTEGRACIONISTAS Y AUTONÓMICAS
}

\author{
BEING INDIGENOUS AND PEASANT IN THE HISTORICAL \\ CONTEXT OF MÉXICO: A CLOSE UP TO THE INTEGRATING \\ AND AUTONOMOUS PERSPECTIVES
}

*Licenciado en Filosofía por el Instituto de Estudios Superiores Tomás de Aquino (IESTA) que corresponde al Seminario de la Arquidiócesis de Tuxtla Gutiérrez, Chiapas México y candidato, mexico,y canCiencias a Maestro er Rural por la Universidad Autónoma Chapingo, Texcoco de Mora Estado de México.

\section{Por: Adrián Alexander Zuleta Cisneros*}

Recibido: 26 de octubre de 2015 - Aprobado: 19 de julio de 2016

\section{RESUMEN}

El presente trabajo es un análisis sintético-crítico de la historia de México con respecto al ser indígena-campesino en dos aspectos básicos: integración y autonomía. Así también, se hace una reflexión concreta y ontológica de lo que, como hombres y mujeres representan en el contexto cultural, político y económico de México. La finalidad es generar una reflexión para abrir nuevos debates sobre la situación actual de los pueblos indígenas-campesinos de México y con ello, forjar una historia más justa y digna para dichos pueblos.

Palabras Claves: Ser indígena-campesino, Integración, Autonomía.

\begin{abstract}
This paper is a synthetic-critical of the history of Mexico with respect to being indigenous-peasant in two basic aspects analysis: integration and autonomy. Additionally, it is a concrete and ontological analysis of what men and women represent in the political, economic and cultural context of Mexico. The aim is to generate a reflection to open new discussions on the current situation of indigenous-peasant people of Mexico and thus build a more just and dignified history for these people.
\end{abstract}

Key Words: Indigenous-peasant, Integration, Autonomy

\section{Introducción}

l l ser indígena-campesino dentro del contexto histórico de 1 México: Un acercamiento a las perspectivas integracionistas y autonómicas", es un trabajo que centra su interés en reflexionar algunos acontecimientos históricos sobre los condicionamientos sociales, culturales, políticos y económicos sobre la población indígena-campesina. Pero antes, se realiza una reflexión de lo que pudiera entenderse por indígena- 
campesino desde una perspectiva concreta y ontológica. La finalidad es dar una orientación más amplia y crítica de ellos, para comprender los escenarios históricos a los que se han enfrentado. Tal y como dice Lukacs Tertulian, "por eso, antes de entrar en el problema de la ideología debemos darle una mirada al proceso por el cual surgen, ontológicamente, tales demandas y sus formas de respuesta" (1987: 150).

En el segundo punto se aborda una síntesis histórica del ser indígenacampesino en tres momentos esenciales: La colonización, el liberalismo en México y la época revolucionaria y posrevolucionaria. Cabe aclarar que este bosquejo histórico busca entrever las ideas prominentes que afectaron la comprensión de la realidad indígena-campesina y la manera o modo en que se negó su posibilidad de seres íntegros y dignos. De acuerdo a Bonfil, "Durante los últimos cinco siglos (apenas un momento en su larga trayectoria) los pueblos mesoamericanos han vivido sometidos a un sistema de opresión brutal que afecta todos los aspectos de su vida y sus culturas" (1994: 244).

En el tercer y último punto se hace mención de manera esporádica sobre el levantamiento armado del Ejercito Zapatista de Liberación Nacional (EZLN) de 1994 y el caso de Cherán. La finalidad no es hacer un estudio detallado sobre estos levantamientos en contra del sistema político-económico de México, antes bien, es manifestar que hay pueblos en lucha por la reivindicación de sus derechos y su dignidad. Así como dar paso a nuevas reflexiones de estos acontecimientos de forma más analítica y crítica, por ende, más extensa. Ahora bien, revisemos los puntos mencionados.

\section{Fundamentos sobre el ser indígena-campesino.}

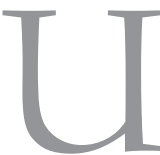

na de las dificultades más grandes dentro del campo teórico en cuanto a las ciencias sociales, es comprender las particularidades de un grupo social, puesto que, existen grupos humanos que se distinguen por el "modo de ser" 1 en lo que ordinariamente llamamos "vida" o "devenir histórico". Piotr Sztompka sobre este tema, hace un análisis detallado y expone la composición de una sociedad desde dos aspectos o mecanismos que son: el material y el ideal. Los cuales - como hemos dicho - son los que nos permiten entrever por qué una sociedad es distinta respecto a otra y viceversa. Primeramente, el autor explica que dentro del mecanismo material se encuentra aquella expresión que es tangible a los seres humanos. Por lo que redacta, "el mecanismo material opera a través de la supervivencia de objetos, artefactos, organizaciones, producidos por las actividades de generaciones
${ }^{1}$ Un "modo de ser" en el mundo de forma "horizontal" o sea, sin hacer de más o menos a una cultura particular tal y como se podría entender en la "verticalidad" que expone grados de ser o jerarquías que de cierta manera justifica cierta manera, justifica a hegemonía cultural $\mathrm{o}$ bien, el dominio y saqueo de un pueblo 
${ }^{2}$ Ver más en Prieto,

Leopoldo. El hombre

$y$ el animal: nuevas fronteras de la antro-
pología, BAC, Madrid.

Págs. $219-273$. anteriores, pero que envuelven acciones emprendidas por la presente. Está ligado al hecho físico de la duración" (1995: 82).

Consecuentemente, nos detalla el mecanismo ideal cuya explicación se encuentra en aquello que perdura en la mente de los hombres como son las voces hechas memorias y a su vez, transmitidas. O en su defecto, los recuerdos escritos también nombrados historia. Citamos,

El mecanismo ideal opera a través de las capacidades humanas de la memoria y la comunicación. El pasado es preservado porque la gente recuerda fragmentos de él. Primeramente recuerdan sus propias experiencias, pero el alcance de su memoria se amplía de dos formas. Primero, hacia sus contemporáneos, con quienes pueden compartir sus memorias, y de quienes pueden aprender acerca de hechos pasados que no experimentaron personalmente. De esta forma, se logra un depósito de memoria colectiva que se almacena en archivos, bibliotecas, museos. Segundo, el alcance de la memoria se extiende también hacia los predecesores, por medio de los registros históricos de todo tipo, en los cuales las memorias de las generaciones anteriores quedan depositadas. De esta forma, el depósito de memoria colectiva alcanza el pasado profundo, mucho más lejos de lo recolectado por cada uno de los miembros individuales (1995: 82).

En correlación al análisis de Sztompka, inferimos que la sociedad y en particular un grupo social, es comprendido a la luz de su expresión material e ideal y, aún más, puede ser explicada a partir de ello. Empero, a pesar de esto debemos considerar que los seres humanos al poseer libertad y voluntad ${ }^{2}$, se encuentran en constante movimiento $y$, por tanto, son indeterminados. De manera, que el estudio de una sociedad constituye una página de suma complejidad.

Y solo con base a lo expuesto es que intentamos explicar el "ser indígenacampesino"; un concepto que no se limita a la definición abstracta y, sin embargo, se acude a esta para entrever una parte de lo que como grupo social "es" o "significa" en nuestro entorno esencialmente diverso. Es claro que si acudimos a una observación o apreciación de realidad empírica sobre el ser indígena-campesino asumimos al igual que Gamio - citado por Guillermo Bonfil - que, "propiamente un indio es aquel que además de hablar exclusivamente su lengua nativa, conserva en su naturaleza, en su 
forma de vida y de pensar, numerosos rasgos culturales de sus antecesores precolombinos y muy pocos rasgos culturales occidentales (1972: 107).

Pero además es "campesino" por una herencia milenaria y cultural, en la siembra y cosecha del maíz. Bonfil lo expone, "la civilización mesoamericana surge como resultado de la invención de la agricultura [...] El cultivo del maíz constituye un logro fundamental y queda ligado de manera indisoluble a la civilización mesoamericana" (1994: 24, 25). Por lo que se interpreta, el indígena-campesino es un agricultor cuya lengua y cosmovisión es antagónica a la de Occidente. Empero, ise reduce a esto el indígena-campesino? Dejemos que la historia nos lo diga, no sin antes, afirmar que el "ser" no se limita al "hacer", es decir, acudamos a lo ontológico como fundamento de lo histórico.

\subsection{Ontología indígena-campesina.}

I l simple hecho de mencionar el concepto de "ontología" nos refiere a un amplio debate en materia filosófica y cuanto más aún lo es, al auxiliarnos de ella para exponer la constitución formal-abstracta y concreta que emana del ser indígena-campesino. Sin embargo, esto no es una labor imposible pues, la filosofía problematiza sobre el hombre y lo que circunda en él y sobre él. Justificamos,

contra la negación del pensamiento indígena podemos establecer que el pensamiento, la racionalidad y la filosofía no necesariamente deberán ajustarse a los modelos establecidos por Platón, Aristóteles, Agustín, Tomás, Descartes, Hegel, Marx, etcétera. En otras palabras, no puede ser una sola forma lo que determine el carácter filosófico de una reflexión, pues no es un determinado modelo lo que importa reflexionar, sino un problema que se ha de enfrentar una y otra vez en la relación del hombre con su mundo (Magallón, 1991: 19).

Con base en esto, sostenemos que al situarnos sobre el "ser" de lo indígenacampesino nos referimos en primera, a lo que Aristóteles escribe, " $<<$ ser $>>$ $\mathrm{y}<<$ es $>>$ significan que algo es verdadero, $\mathrm{y}<<$ no ser $>>$, no verdadero, sino falso tanto en la afirmación como en la negación (2012: 66). En otras palabras, "ser" es un "alguien" real en cuanto que, es "verdadero" y el "no ser" denota la imposibilidad de un "alguien" en tanto que carece de realidad.

Y la realidad según Zubiri es, "trascendentalmente en su constitución una interioridad y una exterioridad, o, dicho con más precisión una interioridad 
${ }^{3}$ Hacemos mención de lo "temporal" para aludir a

la posibilidad de "ser"

"no". Ya que, afirmar la determinación del "ser" de manera "absoluta" es limitar o coartar es posibilidad de cambio, movimiento o devenir

Hegel detalla sobre este

punto con base a Herá-

clito en la Ciencia lógica,

ABADA Editores, España, Pág. 227. plasmada en una exterioridad" (1966: 236, 237). En palabras simples, la realidad es la conjugación de lo tangible (sensitivo) y lo intangible o abstracto (pensamiento).

Por otro lado, Hegel sostiene que, "ser, puro ser: sin ninguna determinación ulterior. Dentro de su inmediatez indeterminada, él es solamente igual a sí mismo, sin ser tampoco desigual frente a otro: no tiene ninguna diversidad en su interior, ni tampoco hacia afuera [...] El ser, lo inmediato indeterminado, es de hecho nada, ni más ni menos que nada" (2011: 225). Entonces, dilucidamos que para Hegel el "ser" es indeterminación o lo mismo que "nada" que no necesariamente denota imposibilidad, antes bien, emana todo lo contrario, es decir, el "ser" como lo posible.

Y en esa posibilidad es que se consigue "ser" o "no ser" dado que, lo indeterminado es dinamismo, movimiento o devenir. Citamos nuevamente, "El puro ser y la pura nada es lo mismo. Lo que es la verdad no es ni el ser ni la nada, sino el hecho de que el ser, no es que pase, sino que ha pasado a nada y la nada a ser" (Hegel, 2011: 226). Por lo tanto, el ser es la posibilidad, el cambio o la transformación y dentro de la indeterminación, también divisamos la búsqueda por la determinación temporal ${ }^{3}$.

Desde estas perspectivas ontológicas-sintéticas del "ser" - emanadas de Occidente - nos acercamos a una expresión más amplia de lo que se comprende como "ser indígena-campesino". Primero - de acuerdo al filósofo Aristóteles -, ser indígena-campesino es asumir a un "alguien" dotado de "realidad", es decir, constituido de una materialidad y circunstancia. Segundo, es "verdadero" $y$, por ende, innegable dado que su realidad extrínseca es complemento de su realidad intrínseca, esto es, su capacidad pensante y/o cognoscente.

Por ello, sólo resta añadir el aporte de Hegel que - según lo prescrito - "ser" es "nada" y viceversa. "Ser" es indeterminación y posibilidad. Entonces, se comprende que el ser indígena-campesino es sinónimo de indeterminación en cuanto que "puede" autodeterminarse y redirigir su historia más allá de los apelativos y condicionamientos sociales que "otros" les han impuesto. Ejemplos de esto son, Ricardo e Isabel Pozas - citados por Bonfil - que expresan,

Se denomina indios o indígenas a los descendientes de los habitantes nativos de América - a quienes los descubridores españoles, por creer que habían llegado a las indias, llamaron indios - que conservaban 
algunas características de sus antepasados en virtud de las cuales se hallan situados económica y socialmente en un plano de inferioridad frente al resto de la población, y que, ordinariamente, se distinguen por hablar las lenguas de sus antepasados, hecho que determina el que éstas también sean llamadas lenguas indígenas (1972: 110).

Por consiguiente, esta aseveración bate con el "ser" indígena al punto de la minimización. Pero insistimos - de acuerdo a lo establecido - que esta visión sobre el indígena es limitada puesto que, su fundamento denota carencia de reflexión profunda y más grave aún, esclarece subjetividades peyorativas. Semejante a la interpretación de Marx - en otra época y circunstancia cuando se refirió a los campesinos franceses como, "un saco de patatas [...] porque no tenían conciencia de clase" (Citado por Burke, 1987: 77).

Finalmente asumimos que, "ser indígena-campesino" es una expresión que refiere a lo "humano" en su máxima expresión que excluye cualquier distinción racial. En este sentido, ser indígena-campesino remitirá indiscutiblemente a lo complejo que se constituye por lo espiritual ${ }^{4}$, un o muchas formas de pensamiento, una geografía-entorno, una situación temporal-especifica (temporalidad), indeterminación y/o posibilidad (devenir histórico), etc.

\subsubsection{Ontología relacional y ontología política.}

7 i bien es cierto, el punto anterior abre una reflexión conceptual del "ser" con las perspectivas de los filósofos de Occidente y con ello, nos aproximarnos a una comprensión de la realidad indígena-campesina en cuanto a su papel en la historia económica, política y cultural de México. Sin embargo, tales categorías nos permiten entrever el ser indígena-campesino como un grupo aislado y concretamente, antropocéntrico. Los cuales no tienen motivos de vida o en su defecto, han sido asediados sin razón alguna. Empero sabemos que no es así.

Por esta razón hacemos alusión a la ontología relacional que Arturo Escobar explica, "en estas ontologías, los territorios son espacios-tiempos vitales de toda comunidad de hombres y mujeres [...] también son los espacios-tiempos de interrelación con el mundo natural que circundan y es parte constitutivo de este" (2014: 103). En otras palabras, los territorios son escenarios íntimamente ligados a los hombres y mujeres, y viceversa.

En este contexto la realidad no está fragmentada, antes bien, permanece unificada pues, de los hombres y mujeres emana un sentido profundo de
${ }^{4}$ Esta afirmación no gira en torno a la visión de una religión en concreta sino a la expresión natural del hombre por lo incomprensible o trascendente. 
Adrían Alexander Zuleta Cisneros

respeto por la tierra y lo que ella posee. De ahí que se diga, "dentro muchos mundos indígenas y algunas comunidades afrodescendientes de América Latina, esos espacios materiales se manifiestan como montañas o lagos que se entiende tienen vida o son espacios animados" (Escobar, 2014: 103).

No obstante, cuando esto no es aceptado o percibido por otras miradas u otros mundos ideológicos y culturales, se justifica el saqueo y la hegemonía sobre los territorios, y sobre quienes la habitan. De manera que, con la visión de la "modernidad" ya no solo hablamos de indígenas-campesinos como hombres y mujeres en íntima relación con el territorio del que emerge un sentir y su porvenir (vida), sino que este territorio y lo que hay en él comprende un aspecto político cuyo fin tiende a la explotación que, por ende, se sitúa en el plano meramente económico.

Por lo tanto, es importante reconocer que la ontología relacional aunada a la ontología política, nos ayuda a comprender la relación entre los hombres con los territorios y los distintos mundos $\mathrm{y}$, asimismo, nos permite reflexionar $\mathrm{y}$ replantear la defensa de los territorios o la vida que evidentemente consolidan un mundo - como se ha dicho - entre muchos mundos. De esto se dice concretamente, "la ontología política re-sitúa a este mundo moderno como un mundo entre muchos otros mundos" (Escobar, 2014: 108).

Ahora bien, después de habernos situado en una reflexión sobre la complejidad humana y en específico, el ser indígena-campesino de México. Veamos la historia de lo que, ante nuestra reflexión "ideal" filosófica-ontológica, ha ocurrido desde dos aspectos esenciales: la integración (asimilación y aculturación por el Estado) y la autonomía (autodeterminación).

\section{Historia del ser indígena-campesino: Síntesis histórica.}

El filósofo e historiador François Châtelet en su labor intelectual escribió,

en la actualidad entendemos al hombre como ser histórico. Sabe - al menos en la práctica - que sus gestos, sus decisiones, sus palabras, son elementos de una totalidad dinámica irreversible y significativa; que cada momento de su existencia resulta de su pasado y determina su futuro, que el $<<$ curso del tiempo $>>$ no es el simple marco vacío de su presencia sino el lugar impuesto donde se desarrolla dramáticamente su ser (1979: 01). 
Es decir, la historia tiene como fundamento el dinamismo del hombre y en concreto, su existencia. Una existencia que se ve condicionada por el tiempo pues, la vida de un hombre es finita en cuanto que, al cesar su aliento biológicamente se transforma en otros elementos (físico-químicos) que, desde luego, irrumpen con la condición de existencia humana como tal. Sin embargo, el autor también nos muestra que la historia inmortaliza la vida de los hombres o de una época puesto que, permanecen en los escritos y en la memoria de sus generaciones posteriores. Citamos:

En la medida en que todo dato humano se produce en la esfera del devenir, es decir, en ese dominio único en el que cada momento se presenta como decididamente diferente y nuevo, en el que está encadenado, por su misma manera de ser, al que le ha precedido y al que le seguirá, en el que el tejido de la vida humana es el acontecimiento, toda mirada más allá del tiempo supone una referencia al tiempo y se construye quizás en contra de él, pero siempre a partir de él y, también, en él (Châtelet, 1979: 4, 5).

Ahora bien, el ser indígena-campesino a lo largo del tiempo ha jugado distintos papeles dentro de la historia de México ya sea, a nivel político, económico y cultural. Por eso, damos paso a una revisión sintética-crítica de lo que concreta e ideológicamente ha sucedido con los pueblos originarios y, asimismo, poner en tela de juicio las perspectivas integracionistas y autonómicas.

\subsection{La colonización y la circunstancia indígena.}

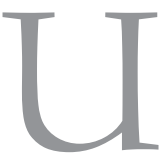

- n estudio más riguroso de la historia indígena partiría desde antes de la colonización en los pueblos de América y en concreto, de México. Sin embargo, dado que nuestro objetivo es debatir a partir de la colonización española partimos de esta afirmación, "el México actual no se entiende sin sus indios" (Torres, 2003: 161). Dicho de otro modo, México es un país que se diferencia de otros países por los pueblos originarios ${ }^{5}$ que actualmente residen en él. Pero también porque ellos constituyen la base histórica-cultural del país. Así también, es evidente que las problemáticas de México no pueden ser entendidas en su totalidad si ignoramos o descartamos la circunstancia indígena-campesina. Hay que recordar que esto deviene desde el período prehispánico, el cual señala la ausencia de una nación mexicana como tal. Respecto a esto Bonfil escribe, "consolidar la nación significó, entonces, plantear la eliminación de la cultura real de casi todos, para implantar otra de la que participaban sólo unos cuantos [...] era un modelo diferente, era otra civilización" (1994: 104). 
${ }^{\circ}$ Ver más en Korsbaek y Sámano, El indigenismo en México: Antecedentes $y$ actualidad, $\mathrm{Ra} \mathrm{Xi}-$ mhai, México, 2007 Pág. 199.

${ }^{7}$ Se refiere a los terrenos situados a las salidas de los poblados durante el período colonial, exitum: Salida. Difiere del significado $y$ sentido otorgado por la legislación agraria surgida en Revolucion mexican de 1910. Véase en Hinojosa, José (1983) Jurídica. Anuario de Departamento de Derecho de la Universida Iberoamericana no.15:

"El concepto de ejido en la legislación mexicana", UNAM, México, 1983, Págs. $173-186$
La necesidad de esta minoría se justificaba con la premisa de que el ser indígena (sin acepción campesina todavía) era un ser inferior, deshumanizado. Por ejemplo, "Clavijero aludía varias veces al inglés William Robertson y al prusiano Cornelius de Paw. Los dos se referían a los indígenas de México y en general de América pintándolos como seres primitivos carentes de cultura (León Portilla, 1992: 16).

Con esta premisa de seres inferiores, los indígenas fueron sometidos y, por ende, saqueados de sus tierras y explotados laboralmente. Luis Villoro agrega, "el pueblo trabajador, constituido por indios y "castas" base de la pirámide social, sólo compartía la extrema miseria" (1939: 38). Empero, la discusión sobre el ser indígena y su dignidad no cesó, Bartolomé de las Casas y Juan Ginés de Sepúlveda realizaron un debate en el año de 1550 en Valladolid, España ${ }^{6}$ que abrió paso a la reconfiguración de leyes establecidas como: "Las Leyes de Burgos 1512, las Leyes Nuevas de 1542 y, en general, en las Leyes de Indias, por primera vez publicadas sistemáticamente en 1681, hasta la independencia en 1821 [...]" (Korsbaek y Sámano, 2007: 199).

Leyes por las cuales, los indígenas padecieron la encomienda, el requerimiento y los tributos obligatorios. En este contexto, el indígena pasó de ser un alguien inferior a un esclavo o bien, un forzado colaborador de la colonia española.

Y con ello, el surgimiento de la nueva propiedad y, por tanto, del ejido ${ }^{7}$, base del sistema que posteriormente surge. Esta fase demuestra que la relación de desigualdad económica y dependencia política reposaba sobre la base del reconocimiento parcial a la realidad previa de la llegada de los colonizadores (Torres, 2003: 162).

Esta conformación del ejido también llamada propiedad comunal significó una dicotomía en cuanto a la propiedad de la tierra; por un lado, estaba situada la hacienda que comercializaba al interior y exterior del país, además de asediar a la contraparte, es decir, las comunidades indígenas. Frente a esta situación opresiva, "la comunidad indígena encontró un arma de defensa social en una institución de una impresionante efectividad y adaptabilidad: esta institución sería después llamada el sistema de cargos" (Korsbaek y Sámano, 2007: 200).

Hay quienes sostienen que la derrota y este padecimiento del ser indígena se debió a que antes de la colonia española, estos ya estaban vencidos por su "atraso" o más grave aún, "retraso". Un teórico sobre esto es Samuel Ramos 
que escribe, "desde antes de la conquista los indígenas eran reacios a todo cambio, a toda renovación. Vivían apegados a sus tradiciones, eran rutinarios y conservadores. En el estilo de su cultura quedó estampada la voluntad de lo inmutable" (2012: 36).

Es probable que semejantes ideas hayan abundado en la mente de los colonizadores y por ello, justificaron la violencia y la integración del indígena al "modo de ser" de estos, pero no con la finalidad de resignificarlo, antes bien, para explotarlo - como anteriormente hemos dicho - mediante otra premisa de "obediencia". De ahí que los colonizadores españoles hayan trasplantado la filosofía y la religión a través de la evangelización o catequización cristiana ${ }^{8}$.

\subsection{El liberalismo frente al contexto indígena.}

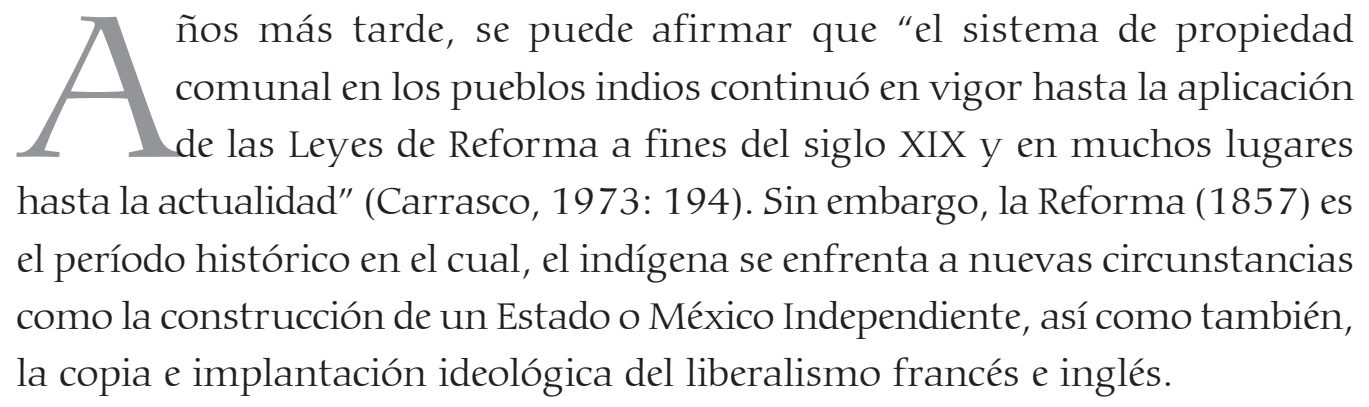

Cabe destacar que la implantación ideológica del liberalismo francés e inglés al contexto social, político y económico de México representó el intento de edificación nacional, es decir, se buscó instaurar la unificación del país mediante un nacionalismo integracionista con la finalidad de borrar el pasado indígena y así, crear una sociedad mestiza como sinónimo de progreso. Sin duda alguna, "en la versión del liberalismo que podemos llamar dura, se excluye toda consideración cultural en la determinación de la condición ciudadana" (Díaz, 1998: 03). De ahí que el ser indígena haya venido a representar una perspectiva de "rezago".

Sin embargo, no hay que olvidar que antes de la adopción del liberalismo a México, los indígenas aunado a los criollos habían luchado por independizarse de la Corona española pese a que, los dirigentes de la lucha no hayan tenido más que intereses muy particulares. Octavio Paz al respecto dice, "Así pues, la lucha por la Independencia tendía a liberar a los $<<$ criollos $>>$ de la momificada burocracia peninsular, aunque, en realidad, no se proponía cambiar la estructura social de las colonias" (2011: 132).

${ }^{\beta}$ Ver más en Ibargüengoitia, Antonio. Suma filosófica mexicana, Edit. Porrúa, México, 2006 Pág. 54. 
En cuanto al liberalismo vemos una fuerte necesidad no solo de consolidar el proyecto de nación sino un proyecto racial o, mejor dicho, racistadiscriminatorio. En ese sentido, Gómez Izquierdo reafirma, "A partir de entonces el concepto mestizo, como base de la identificación nacionalista de México, se inscribe dentro del marco del modelo de percepción asimétrico propiamente racista. Se trata de una identidad nacional-racista, en este caso, dirigida contra su propia población" (2011: 52).

Asimismo, la población indígena o el ser indígena a pesar de ser visto como "rezago" y/o "atraso" para el país, no apagó su espíritu de lucha por la reivindicación de su "ser". En otras palabras, pese a ser minimizado con miras a la "eliminación" por la vía racial - aculturación y mestizaje - luchó contra el sistema políticohegemónico para hacerse respetar. Empero, más allá de ser respetado fue tomado por salvaje y, por ende, temido. El autor Gómez Izquierdo escribe:

Es interesante recordar que Pimentel escribe su Memoria 16 años después de la llamada Guerra de Castas (1847-1848), tiempo en que el indio dejó de ser percibido como un ser inerte y agachado para adquirir de pronto las dimensiones de la más temible amenaza para la civilización blanca, sobre todo, por el obstáculo que encarnaba para la expansión del capitalismo industrial (2011: 58).

\subsection{La época revolucionaria y posrevolucionaria.}

on el paso de los años no desaparece el ambicioso proyecto de aculturar al indígena hasta convertirlo en un ser "eficiente", "civilizado" y en concreto, "mestizo". Y con ello, tampoco desaparecen los problemas de tierra, la explotación y la desigualdad. Situación que nuevamente genera un descontento en la población indígena hasta detonar en la lucha interna llamada Revolución Mexicana (1910). Esta lucha figuró para el indígena la promesa de justicia, tierra y libertad bajo el discurso de Zapata:

El capitalista, el soldado y el gobernante habían vivido tranquilos, sin ser molestados, ni en sus privilegios ni en sus propiedades, a costa de un pueblo esclavo y analfabeto, sin patrimonio y sin porvenir, que estaba condenado a trabajar sin descanso y a morirse de hambre y agotamiento, puesto que, gastando todas sus energías en producir tesoros incalculables, no le era dado contar ni con lo indispensable siquiera para satisfacer sus necesidades más perentorias (Zapata citado por Colmenares, 1990: 346). 
Pero, es sabido que cuando los ideales se convierten en intereses particulares, las problemáticas sociales, políticas, económicas y culturales en nada cambian, solo se transforman en nuevas contrariedades. En este sentido, "la Revolución Mexicana tampoco fue la revolución de los indígenas, sino de nuevo de los mestizos, los rancheros y hacendados mexicanos, es decir, de la burguesía agraria" (Korsbaek y Sámano, 2007: 200).

Entonces se intentó atender al indígena y no necesariamente para favorecerle sino para tranquilizarle y controlarle, de manera que no despertara con violencia ante cualquier abuso que pudiera estar enmascarado de progreso y bienestar. Argumentamos,

las élites volvieron sus ojos hacia el indio, renovaron su paternalismo y prometieron llevar a cabo su redención. El $<<$ alma indígena $>>$ se convirtió en objeto de estudio para la ciencia antropológica indigenista que quería, a partir del conocimiento científico del indio en todos sus aspectos, elaborar un programa de asimilación integral (Gómez, 2011: 77).

Por consiguiente, el gobierno de ese entonces acudió a intelectuales como el antropólogo Manuel Gamio (1883 -1960)9 quien, “apoyaba la integración socioeconómica y cultural de los grupos indios en la vida nacional" (Báez, 2010: 58). Esto significó, la institucionalización política-económica y cultural del indígena al Estado "mexicano" de modo que, se pudieran ajustar a los intereses gubernamentales.

Consecuentemente, aparece el diplomático o político Moisés Sáenz con una perspectiva aparentemente contraria a la de Gamio pues, "prefería impulsar el cambio socioeconómico, reforzando la conciencia rural y la autodeterminación india" (Báez, 2010: 58). Sin embargo, es evidente que estas perspectivas antropológicas y/o teóricas respecto al indígena buscaban de cierta manera "integrarlo" al proyecto nacionalista que durante el liberalismo y la Revolución mexicana venía creciendo o tomando fuerza y era, el de forjar una patria cuya base ideológica, política, económica y cultural fuera "homogénea".

Bonfil Batalla dice: "Pero el fin último no está en duda, ni el indigenismo contradice en nada el proyecto de país que la Revolución triunfante ha ido cristalizando: se trata de incorporar al indio, es decir, desindianizarlo, hacerlo perder su especificidad cultural, histórica. El asunto es como hacerlo mejor" (Bonfil, 1994: 171).

${ }^{9}$ Fue el primer encargado de la Dirección de Estudios Arqueológicos y Etnográficos del nuevo gobierno mexicano en 1917 que dependió del Ministerio de Agricultura. Ver más en Báez, Mariano, De indígenas a campesinos: Miradas antropológicas Miradas antropologica de un quiebre paradig mático, RURIS Vol. 3 2010, Pág. 56. 
${ }^{10}$ Ibíd. 7. Pág. 205. El primer coordinador indigenista (CCI) en San Cristóbal de las Casas, Chiapas en 1951.

${ }^{11}$ Probablemente el concepto "casta" no sea el más adecuado para ese período histórico, sin embargo, el autor as lo redacta para hace una analogía entre el

pasado y el presentehistórico en el cual este se encontraba.

${ }^{12} \mathrm{En}$ México fue fundado por la Ley el 10 de noviembre de 1948 para sustituir al Departamento Autónomo de Asuntos Indígenas (DAAI) que se había (DAAI) que se había
creado trece años ancreado trece años anentrado en decadencia. Vázquez citado por Korsbaek y Sámano, Ibíd. 7, Pág. 203.

${ }^{13}$ Ver más en Sosa, Margarita y Henríquez Cristina (Coord.). Instituto Nacional Indigenista. Comisión nacional para el desarrollo de los pueblos indígenas (1948 - 2012), CDI, México, 2012, Págs. 7-10.

${ }^{14}$ bíd. 7, Pág. 213.
Posteriormente surgen otros intelectuales como Alfonso Caso (1896 - 1970) y Gonzalo Aguirre Beltrán (1908-1996) ${ }^{10}$, quienes abordaron la perspectiva indígena de manera semejante y complementaria a la visión de Gamio y Sáenz. Si bien es cierto, Alfonso Caso consideró que el indígena "tenía que convertirse en una política de Estado, que tuviera como meta, una vez más, la integración nacional" (Báez, 2010: 59). Así también, asumió que había de "transformar al indio en campesino, es decir, transformar a la comunidad indígena en una comunidad rural más del país impidiendo su segregación y aislamiento" (Báez, 2010: 60).

Mientras tanto, Aguirre Beltrán ya no señaló al indígena como "el superviviente de una cultura en declino, sino como un habitante rural que es explotado como casta ${ }^{11}$ en medio de un sistema capitalista" (Caso citado por Báez, 2010: 60). A pesar de su esfuerzo realizado, "su teoría de integración fue entendida como homogenización étnica, cultural, social, económica y política, que podía ser alcanzada a través de instrumentos como el mestizaje, el bilingüismo, la aculturación y la redistribución de dignidad, riqueza y poder" (Báez, 2010: 60).

Cabe señalar que los aportes o la intervención intelectual realizada por Alfonso Caso y Aguirre Beltrán, abrieron paso a la institucionalización del indígena mediante la creación del Instituto Nacional Indigenista (INI) ${ }^{12}$ el 4 de diciembre de $1948^{13}$. El mismo que años más tarde - mayo del $2003^{14}$ - desaparece como institución de "asistencia" a los pueblos indígenas.

Ambos acontecimientos históricos generaron diversas críticas pues, la institucionalización representó un logro para el Estado: el "control" ideológico, político, económico y cultural de los pueblos indígenas. Y la desinstitucionalización dejó ver la situación real sobre los pueblos indígenas, es decir, el desinterés del Estado por las verdaderas problemáticas indígenas como son la pobreza, la salud y la desigualdad, etc.

Hay que señalar que en este período los indígenas -según lo anterior en Alfonso Caso- eran vistos bajo el adjetivo campesino o al menos en esto tenían que transformarse. Pero cabe recordar que los pueblos originarios -como al principio vimos- ya eran de por sí campesinos, solo que ideológicamente (racista) suena "menos denigrante". Ante esto Contreras señala, 
en esta lógica, para los estados, los términos "indígena", "étnico" y "nativo" significan gente insuficiente que requiere de las obras de beneficencia y evangelización, así como de la protección integracionista. A la par, "campesino" es una denominación clasista de carácter laboral civilizado. Según los ideólogos de ésta corriente, son términos que "reivindican" la condición inferior que significa ser indio (2000: 137) ${ }^{15}$.

Por lo tanto, en esta afirmación se vislumbran dos ideas; la primera, es que el indígena no dejó de ser visto como un "ser inferior" -según debe ser tratado y asistido como tal- pese a que, en la Colonia se haya debatido sobre su "ser" y dignidad. La segunda, la denominación de "campesino" acuñada -bajo la perspectiva del Estado- sobre los pueblos indígenas es una forma "irracional" de intentar negar la realidad indígena. Porque hemos escrito con insistencia que, el ser indígena a lo largo de la historia de México representa un "atraso" o "rezago" cultural, político y económico del país. Además, al Estado le resulta más sencillo tergiversar un concepto que atender los sectores marginados de la nación.

Pero este "atender" los sectores marginados -que pueden ser tanto zonas rurales como urbanas- ha significado para este (el Estado mexicano) el paternalismo y asistencialismo. Sabemos que, al institucionalizar a los grupos sociales se les imponen una serie de normas o pautas a seguir. En México las instituciones que han tomado este papel son "Prospera", "Oportunidades", entre otras.

Evidentemente, estos mecanismos como el paternalismo, el asistencialismo y, además, la represión que emanan de la institucionalización, son los que tienden a persuadirlos y a reducirlos a un estado de conformismo y, por consiguiente, se imposibilitan a pensar en la posibilidad de ser autónomos e independientes con respecto a la política y economía dominante que ejerce el poder mexicano sobre ellos.

Con esto, es evidente que el Estado mexicano no solo ha buscado el dominio de los pueblos indígenas, sino que, también dentro de su modelo capitalista (adoptado) han existido intereses ligados a las zonas rurales que, en su mayoría, son habitadas por estos pueblos indígenas. Intereses que se centran en la materia prima (tierra, suelo, flora y fauna) ya que, "la tierra es una mercancía y un recurso productivo cuyo destino y uso debe decidirse en 
función de consideraciones como productividad y relación costo-beneficio" (Contreras, 2000: 142). Y en esta dinámica capitalista, el indígena que es campesino por su labor con el campo (indígena-campesino) solo ha fungido en razón de la producción y coartado de todo bienestar social. Por lo que, el ser indígena-campesino tanto en la revolución y posrevolución ha sido, una vez más, negado y apreciado como un "objeto" de producción y enriquecimiento para quienes han estado al frente del Estado-Nación.

\section{El ser indígena-campesino en lucha por la autonomía.}

nte los embates y sometimientos históricos, económicos, políticos
y culturales que el ser indígena-campesino ha padecido, el "ser" de
ellos - de los pueblos indígenas- por ser posibilidad e indeterminación de acuerdo a los enfoques ontológicos, ha despertado más de una vez como signo de esperanza por una vida mejor, más digna y más justa. Un ejemplo de esto, es el levantamiento armado del 1 de enero de 1994 en los Altos de Chiapas, México, el cual estuvo a manos del EZLN y constituido esencialmente pos los pueblos indígenas-campesinos de los Altos de Chiapas, es decir, las zonas más deplorables del estado.

Por eso, hay quienes escribieron que, "la guerra de Chiapas es un ejemplo reciente de la vitalidad de ese México que responde, desde la dimensión localregional, a los embates de un capitalismo salvaje de dimensión global" (Báez, 2010: 69). O bien, "el levantamiento del Ejército Zapatista de Liberación Nacional (EZLN) se convierte en la expresión más explosiva y contradictoria de ese discurso y, como tal, manifestativa de sus límites y fracturas" (Villafuerte, 2002: 31).

En cuanto a las comunidades zapatistas, las voces de quienes han padecido y ejercido esta lucha, han sido escuchadas y transcritos para permanecer en la historia, la memoria o el recuerdo de sus descendientes y de cualquier comunidad indígena-campesina dispuesta a romper con el yugo del Estado mexicano. Citamos ${ }^{16}$ :

${ }^{16} \mathrm{La}$ siguiente cita $\mathrm{CO}-$ rresponde al fragmento de un testimonio de una autoridad de un municipio autónomo zapatista. Estos testimonios fueron recopilados y escritos por Fernández Paulina en Justicia autónoma zapa Jisticia autónoma zap tista. Zona Selva Tzeltal Ediciones Autónom@s, México, 2014.
Nosotros como autónomos, para cuidar de nuestro territorio porque nosotros pertenecemos, y no viene otra persona fuera que nos viene a controlar porque ya lo vimos de parte del gobierno no nos resuelve nuestros problemas, y por eso nosotros como autónomo, nosotros mismos tenemos que controlar y vigilar nuestros terrenos, todo lo que pertenece. Por eso el pueblo eligió 
autoridades para que controle y vigile el territorio, pa' que ya no el gobierno que nos venga a vigilar y nos venga a poner estas cosas, no, sino que nosotros tenemos que ver, tenemos que controlar ... (Fernández, 2014: 110).

Actualmente podemos decir que, a pesar de que algunas comunidades indígenas-campesinas de los Altos de Chiapas formen parte de los Municipios Autónomos Revolucionarios del Ejército Zapatista (MAREZ), no significa que la lucha esté terminada y por ello, tengan que vivir como si nada aconteció. Por el contrario, para ellos la lucha permanece o de lo contrario volverían a manos de quienes históricamente los oprimió: el Estado.

Otro ejemplo de lucha por la autonomía o la ruptura con el Estado mexicano y su modelo hegemónico- por tan solo mencionar- está Cherán que es un municipio de Michoacán, México. Exponemos,

el 15 de abril de 2011, los comuneros de Cherán dijeron iBasta! La problemática del corte de madera de manera ilegal por parte de los grupos organizados no es nueva en la región, tiene una historia de varias décadas. Lo nuevo entonces no es la tala clandestina, sino su relación, vinculación, apoyo, forzado o no, con grupos del crimen organizado (Ventura, 2012: 160).

Tras la explotación de sus recursos y la violación de sus derechos se vieron obligados a generar la ruptura con el Estado y actualmente permanecen en disputa para que, al igual que, el EZLN puedan constantemente reivindicar su "ser", esto es, sus posibilidades, sus derechos y en concreto, su dignidad como hombres y mujeres en el plano de lo universal ${ }^{17}$.

Por lo tanto, concluimos este punto con la afirmación que Héctor Díaz Polanco escribe,

no existiría conflicto alguno si los grupos étnicos planteasen el ejercicio de sus derechos como cristalización política propia, al margen del Estado-nación en que se encuentran incluidos. El conflicto se configura en tanto que la autonomía es planteada no fuera, sino en el marco de la nación que, a su vez, es pluricultural en un sentido amplio (1998: 2,3).

${ }^{17}$ No hacemos referencia a la homogenización sino a la idea de que ninguna diferenciación étnica y cultural tiene que ser un motivo de discriminación o exaltación, es decir, es metacion, es decir, es menester un trato digno distintas culturas. 
${ }^{18}$ Detallamos, "La defensa del espacio territorial, de la $<<$ madre tierra $>>$, del derecho de conservar la autonomía comunitaria, costumbres y gobierno propio, ha sido considerada un desafío de la $<<$ barbarie $>>$ a la $<<$ civilización $>>$, motivando accione que en variada manifestación estratégica han estado dirigidas a someterlo y despojarlo de sus tierras. Ante la política etnocida, los yaquis han tenido múltiples respuestas en su lucha para existi en libertad, afirmando el derecho a la diferencia y ser dueños de sus destinos". Retomado de Velasco, José en Autonomía y territorialidad entre los yaquis de Sonora, México, CESLA, Polonia, 1992, Pág. 147.

${ }^{19} \mathrm{El}$ convenio citado fue aprobado por la Cáma-

ra de Senadores del H.

Congreso de la Unión el

día 11 de julio del 1990

según decreto publica-

do en el Diario Oficial

de la Federación el día

3 de agosto del propio

año". Gálvez Ruiz, Xó-

chitl, Convenio 169 de la

OIT sobre pueblos indí genas y tribales en países independientes, $\mathrm{CD}$ México, 1989, Pág. 03.
En palabras simples, el respeto por la libertad de ser y autodefinirse de los pueblos indígenas-campesinos, así como, el ejercicio de sus derechos y organización social, económica y política es la clave para romper con cualquier conflicto ante el Estado. Por otro lado, la coerción de este respeto y conjunto de posibilidades indígenas-campesinas, significa en lo absoluto, la guerra interminable entre la disyuntiva indígena y nación (de acuerdo a los antecedentes históricos).

\section{Conclusión}

olo queda añadir que el ser indígena-campesino visto más allá (ontológicamente) de su condicionamiento material (económico-político) 1 puede transformar el entorno en el que se encuentra, dicho de otra forma, mejorar su calidad de vida. Para lograr esto, tendrán que tomar consciencia de su "ser" tal y como, el EZLN, Cherán, los yaquis ${ }^{18}$, entre otros, lo han demostrado.

Es menester recalcar que los conflictos entre los pueblos indígenas-campesinos y el Estado mexicano pueden ser evitados siempre y cuando, se reconozcan los universos teóricos que apoyan la autonomía y autodeterminación de ellos. Por ejemplo, el convenio 169 de la OIT"19 inscribe en el artículo 2: "Los gobiernos deberán asumir la responsabilidad de desarrollar, con la participación de los pueblos interesados, una acción coordinada y sistemática con miras a proteger los derechos de esos pueblos y a garantizar el respeto de su integridad" (Gálvez, 1989: 06).

Asimismo, está la Declaración de las Naciones Unidas sobre los derechos de los pueblos indígenas que emite en el artículo 3: "Los pueblos indígenas tienen derecho a la libre determinación, tienen derecho a la autonomía o al autogobierno en las cuestiones relacionadas con sus asuntos internos y locales, así como a disponer de medios para financiar sus funciones autónomas" (ONU, 2007: 05).

Respecto a los universos teóricos regionales-locales se encuentran los Acuerdos de San Andrés Larrainzar, Chiapas, México, los cuales han sido negados y, sin embargo, siguen latentes demandando autonomía y autodeterminación, citamos No. 157: "Se reconoce el derecho a la libre determinación y la autonomía de los pueblos indígenas, en tanto colectividades con cultura diferente y capacidad para decidir sus asuntos fundamentales en el marco del Estado Nacional" (Guzmán et al, 2003: 75). Lo citamos en tsotsil: 
T sots tsakbil ti yich'el ta muk'jamal snopel xchapel xkuxlej xchi'uk yich'el sbaik ta muk' stukik ti slumal bats'i jnaklumetike, bu ti yu'un ja'jchop jnaklejetik jelel stalel xkuxlejik xchi'uk xu'yu'nik snopel xchapel k'usi tsots sk'oplal ta xkuxlejik jech k'uchal albil sk'oplal nitil tsakalik ta sjunul slumal Mejikoe (2003: 75).

En suma, el ser indígena-campesino tras las vivencias de marginación histórica - según hemos analizado- resaltamos que la prioridad no es tanto buscar un lugar para ellos puesto que lo tienen. Más bien, es necesario reconocer el lugar que poseen y respetarlo para construir una armonía histórica entre la diversidad social-cultural, política y económica. Consideramos que esto puede parecer utópico e iluso, pero es posible.

La tarea es crear conciencia ética y moral tanto para quienes dirigen el Estado como en los pueblos considerados no indígenas e indígenas. Sin esto, la historia continuará escribiéndose con tintas de violencia e injusticia. Así lo ha descrito Murray Bookchin desde su circunstancia histórica, "la sociedad con la que nos enfrentamos en numerosos países no es racional sino racionalizada; una sociedad administrada excesivamente y movilizada burocráticamente hasta un punto tal que amenaza con asfixiar los últimos vestigios de individualidad, personalidad y unicidad" (1978: 04).

\section{BIBLIOGRAFÍA}

Báez, Mariano. (2010). De indígenas a campesinos: Miradas antropológicas de un quiebre paradigmático, RURIS Vol. 3, México.

Bonfil, Guillermo. (1972). El concepto de indio en América: Una categoría de la situación colonial, Anales de Antropología Vol. 9, UNAM, México.

Bonfil, Guillermo. (1994). México profundo: Una civilización negada, Grijalbo, México.

Bookchin, Murray. (1978). Los límites de la ciudad, Ediciones H. Blume, España.

Burke, Peter. (1987). Sociología e historia, Alianza Editorial, España.

Carrasco, Pedro José. (1973). "La transformación de la cultura indígena durante la colonia" en Miranda, José y Zavala, Silvio, La política indigenista en México- métodos y resultados, INI, México.

Châtelet, François. (1979). El nacimiento de la historia. La formación del pensamiento historiador en Grecia, Siglo XXI, México. 
Contreras, Miguel A. (2000). Los indígenas y la globalización en América Latina, Centro de Investigación y Documentación sobre América Latina en Universidad de París III Sorbona Nueva, Francia.

Díaz Polanco, Héctor. (1998). Autodeterminación, autonomía y liberalismo, ALAI (América Latina en movimiento), México.

Escobar, Arturo. (2014). Sentir pensar la tierra, Nuevas lecturas sobre desarrollo, territorio y diferencia, Ediciones UNAULA, Colombia.

Fernández, Paulina. (2014). Justicia autónoma zapatista. Zona Selva Tzeltal, Ediciones Autónom@s, México.

Gálvez Ruiz, Xóchitl. (1989). Convenio 169 de la OIT sobre pueblos indígenas y tribales en países independientes, CDI, México.

Gómez, Jorge y Sánchez, María (2011). La ideología mestizante, el guadalupanismo y sus repercusiones sociales, BUAP - UIA, México.

Guzmán, Alonso et al (Coord.). (2003). Los acuerdos de San Andrés, Coneculta, México.

Hegel, Georg. (2011). Ciencia de la lógica, Abada Editores, España.

Hinojosa, José. (1983). Jurídica. Anuario del Departamento de Derecho de la Universidad Iberoamericana No.15: "El concepto de ejido en la legislación mexicana", UNAM, México.

Ibargüengoitia, Antonio. (2006). Suma filosófica mexicana, Edit. Porrúa, México.

Korsbaek, Leif \& Sámano, Miguel. (2007). El indigenismo en México: Antecedentes y actualidad, Ra Ximhai, México.

León Portilla, Miguel. (1992). Encuentro de dos mundos, Conferencia internacional: "Reescribiendo la historia", San Antonio del Mar, Baja California, 8 de febrero del año indicado.

Lukacs, Tertulian. (1987). La ontología del ser social (Traducción del cap. 1 del volumen II por César E. Peón), UACh, México.

Magallón, Mario. (1991). Dialéctica de la filosofía latinoamericana. Una filosofía en la historia, UNAM, México.

Navarrete, Federico. (2008). Los pueblos indígenas de México. Pueblos indígenas del México contemporáneo, CDI, México.

ONU. (2007). Declaración de las Naciones Unidas sobre los derechos de los pueblos indígenas.

Paz, Octavio. (2011). El laberinto de la soledad, F.C.E., México.

Prieto, Leopoldo. (2008). El hombre y el animal: Nuevas fronteras de la antropología, BAC, Madrid. 
Sosa, Margarita y Henríquez, Cristina (Coord.). (2012). Instituto Nacional Indigenista. Comisión Nacional para el Desarrollo de los Pueblos Indígenas (1948 - 2012), CDI, México.

Ramos, Samuel. (2012). El perfil del hombre y la cultura en México, Austral, México.

Sztompka, Piotr. (1995). Sociología del cambio social, Alianza Editorial, España.

Torres Carral. (2003). Civilización, ruralidad y ambiente, Edit. Plaza y Valdés, México.

Velasco, José. (1992). Autonomía y territorialidad entre los yaquis de Sonora, México, CESLA, Polonia.

Ventura, María. (2012). Proceso de autonomía en Cherán. Movilizar el derecho, Espiral Vol. XIX no. 55, México.

Villafuerte, Daniel. (2002). La tierra en Chiapas. Viejos problemas nuevos, F.C.E, México.

Villoro, Luis. (1999). El proceso ideológico de la revolución de independencia, Conaculta, México.

Zapata, Emiliano en Colmenares, Ismael - Otros. (1990). "Manifiesto a la nación" en Cien años de luchas de clases en México 1876 -1976 (Tomo 1), Quinto Sol, México. 